\title{
Febre de origem indeterminada em adultos
}

\author{
Fever of unknown origin in adults
}

\author{
José Roberto Lambertucci ${ }^{1}$, Renata Eliane de Ávila ${ }^{1}$ e Izabela Voieta ${ }^{1}$
}

\begin{abstract}
RESUMO
A febre de origem indeterminada clássica é definida pela presença de temperatura axilar maior do que $37,8^{\circ} \mathrm{C}$, em várias ocasiões, pelo tempo mínimo de três semanas e que se mantém sem causa aparente após uma semana de investigação hospitalar. Tal conceito vem sofrendo alterações com o tempo e em decorrência das inovações médicas. Em resposta à evolução do conhecimento e às pressões ambientais, os casos de febre de origem indeterminada são atualmente classificados em quatro síndromes: clássica, nosocomial, no neutropênico, e no paciente infectado pelo vírus da imunodeficiência humana. No presente artigo procuramos definir e atualizar as informações sobre o assunto.
\end{abstract}

Palavras-chaves: Febre. Febre de origem indeterminada. Febre prolongada. Aids. Neutropenia.

\begin{abstract}
Fever of unknown origin has been defined as axillary temperature higher than $37.8^{\circ} \mathrm{C}$ on several occasions, persisting without diagnosis for at least 3 weeks in spite of at least 1 week's investigation in hospital. Lately, the definition has been modified and extended to reflect evolutionary changes in clinical practice. In response to this new evolving environment, cases of fever of unknown origin are currently classified as: classic, nosocomial, in neutropenia, and human immunodeficiency virus-related. The objective of our review was to try and define and to update the information on the subject.
\end{abstract}

Key-words: Fever. Fever of unknown origin. Prolonged fever. Aids. Neutropenia.

A febre de origem indeterminada (FOI) constitui um problema clínico comum e representa importante causa de internações hospitalares. Em um estudo, foi responsável por $8,4 \%$ das internações hospitalares num período de dois anos ${ }^{12}$.

A FOI, classicamente, é definida pela presença de temperatura axilar maior do que $37,8^{\circ} \mathrm{C}$, em várias ocasiões, pelo tempo mínimo de três semanas e após uma semana de investigação hospitalar infrutífera ${ }^{24}$. Essa definição tende a eliminar doenças infecciosas autolimitadas, sobretudo viroses, os pacientes com hipertermia habitual e os casos em que a propedêutica inicial identifica a causa da febre ${ }^{19}$.

0 tempo de propedêutica sem definição diagnóstica para se conceituar a FOI é controverso na literatura. Alguns autores defendem que se reduza para duas semanas de propedêutica sem definição etiológica ${ }^{10}{ }^{18}$. Durack e Street ${ }^{7}$ sugerem a diferenciação da FOI investigada no ambiente hospitalar da investigada em ambulatório. Dessa forma, propõe-se que se considerem três dias de investigação hospitalar e três consultas em ambulatório. Se nesse período o diagnóstico não for esclarecido, define-se FOI (Tabela 1). Em o nosso meio, considerando-se as dificuldades em se obter a propedêutica adequada, nesse intervalo de tempo, sobretudo na rede pública de saúde, esta definição torna-se inadequada.

Durack e Street em $1991^{7}$ sugeriram distinguir a FOI clássica da que se apresenta em outros grupos de pacientes, como os hospitalizados, portadores de HIV e neutropênicos febris. Essa diferenciação se baseia em características intrínsecas desses grupos que devem dirigir o raciocínio para causas de febre que lhes são peculiares. Os idosos também constituem um grupo específico no qual a FOI guarda aspectos próprios.

\section{ETIOLOGIA}

As causas e a frequiência de FOI variam com o tempo, o local onde foi feito o estudo e os critérios conceituais utilizados. 0 uso indiscriminado de antibióticos e antiinflamatórios, erros ou má interpretação de exames laboratoriais e deficiências no sistema de saúde têm se

1. Serviço de Doenças Infecciosas e Parasitárias da Faculdade de Medicina da Universidade Federal de Minas Gerais, Belo Horizonte, MG. Address to: Dr. José Roberto Lambertucci. Serviço de Doenças Infecciosas e Parasitárias/FM/UFMG. Av. Alfredo Balena 190, Santa Efigênia, 30130-100 Belo Horizonte, MG, Brasil.

e-mail: lamber@uai.com.br

Recebido para publicação em 17/7/2005

Aceito em 26/7/2005 
Tabela 1 - Definições de febre de origem indeterminada em diversos grupos ${ }^{11}$

FOI clássica

febre $\geq 37,8^{\circ} \mathrm{C}$ em várias ocasiões

duração $\geq 3$ semanas

ausência de diagnóstico após 3 dias de investigação hospitalar ou três consultas ambulatoriais

FOI nosocomial

pacientes internados

febre $\geq 37,8^{\circ} \mathrm{C}$ em várias ocasiões

ausência de infecção ou doença incubada à admissão

ausência de diagnóstico após 3 dias apesar de investigação adequada (incluindo pelo menos $48 \mathrm{~h}$ de cultura microbiológica)

FOI no paciente neutropênico

neutrófilos $<500 \mathrm{~mm}^{3}$

febre $\geq 37,8^{\circ} \mathrm{C}$ em várias ocasiões

ausência de diagnóstico após 3 dias apesar de investigação adequada (incluindo pelo menos $48 \mathrm{~h}$ de cultura microbiológica)

FOI associada ao HIV

infecção pelo HIV confirmada

febre $\geq 37,8^{\circ} \mathrm{C}$ em várias ocasiões

duração $\geq 4$ semanas (regime ambulatorial), ou $\geq 3$ dias em pacientes internados

ausência de diagnóstico após 3 dias apesar de investigação adequada (incluindo pelo menos 48h de cultura microbiológica)

responsabilizado pelo aumento do número de casos de FOI. Por outro lado, o avanço tecnológico pode tornar o diagnóstico de certas patologias mais fácil e precoce. Assim, o diagnóstico de FOI não deve prender-se a esquemas propedêuticos fixos, pois o médico lançará mão dos métodos complementares mais adequados para cada caso.

Desde a introdução deste conceito, numerosos artigos têm se dedicado à propedêutica das FOIs e à prevalência das diversas patologias como causa das mesmas. A Tabela 2 mostra a distribuição das causas de FOI, considerando-se os grandes grupos de doenças.
Várias condições associam-se à FOI. As infecções permanecem como a principal causa na maioria dos estudos, seguidas pelas doenças neoplásicas e inflamatórias. Apresentamos, na Tabela 3, a descrição das causas encontradas num estudo realizado pelo autor em 1989, no acompanhamento de 54 pacientes $^{13}$.

A febre factícia é rara e ocorre, mais freqüentemente, em profissionais de saúde ou seus familiares do sexo feminino. A indução de febre representa manifestação de doença grave que exige tratamento psiquiátrico adequado. 0 paciente geralmente induz a febre por manipulação do termômetro ou auto-inoculação de material contaminado.

A hipertermia habitual geralmente ocorre em mulheres jovens com reação psiconeurótica. Caracteriza-se por temperaturas entre $37,2^{\circ} \mathrm{C}$ e $37,8^{\circ} \mathrm{C}$ no período da tarde, acompanhada de queixas vagas, e que desaparece junto com a remoção do problema precipitante ou após administração de tranquiilizantes.

\section{CARACTERÍSTICAS CLÍNICAS}

A abordagem do paciente com FOI baseia-se no conhecimento das doenças que podem produzi-la em associação à nosologia prevalecente do ambiente de origem do paciente, definida pelo momento epidemiológico ${ }^{12}$.

Várias séries publicadas realçam a importância de estabelecer-se o diagnóstico.

Numa série de 100 pacientes, 32 faleceram, 20 apresentaram regressão espontânea do quadro clínico, 10 evoluíram para doença crônica e 38 recuperaram-se. Destes últimos, 29 foram submetidos ao tratamento clínico e nove à cirurgia com bons

Tabela 2 - Distribuição das causas (porcentagem) de FOI em adultos por grandes grupos de doenças.

\begin{tabular}{|c|c|c|c|c|c|c|c|}
\hline $\begin{array}{l}\text { Ano de } \\
\text { publicação }\end{array}$ & $\begin{array}{c}\text { Número } \\
\text { de pacientes }\end{array}$ & Autor & $\begin{array}{c}\text { Causas } \\
\text { infecciosas }\end{array}$ & $\begin{array}{c}\text { Causas } \\
\text { neoplásicas }\end{array}$ & $\begin{array}{c}\text { Causas } \\
\text { inflamatórias }\end{array}$ & Miscelânia & $\begin{array}{c}\text { Não } \\
\text { diagnosticadas }\end{array}$ \\
\hline 1961 & 100 & Petersdorf e Beeson & 36 & 19 & 15 & 11 & 7 \\
\hline 1982 & 105 & Larson, Featherstone & 31 & 32 & 9 & 7 & 12 \\
\hline 1989 & 54 & Lambertucci e Pompeu & 43 & 17 & 17 & 19 & 8 \\
\hline 1992 & 85 & Barbado & 13 & 29 & 30 & 9 & 17 \\
\hline 1992 & 86 & Kazanjian & 33 & 24 & 17 & 17 & 9 \\
\hline 1992 & 199 & Knockaert & 23 & 7 & 23 & 22 & 26 \\
\hline 1994 & 153 & Iikuni & 29 & 16 & 30 & 14 & 12 \\
\hline 1994 & 80 & Shoji & 53 & 8 & 15 & 5 & 17 \\
\hline 1997 & 167 & De Kleyn & 26 & 13 & 24 & 8 & 30 \\
\hline
\end{tabular}

Tabela 3 - Causas de febre de origem indeterminada em estudo realizado em 1989 no Brasil, em 54 pacientes ${ }^{13}$.

\begin{tabular}{lcccc}
\hline Infecciosas (43\%) & Neoplásicas (17\%) & Colagenoses (17\%) & Miscelânia (19\%) & Não diagnosticada (8\%) \\
\hline $\begin{array}{l}\text { Tuberculose } \\
\text { Endocardite }\end{array}$ & doença de Hodgkin & lupus eritematoso sistêmico & tireoidite subaguda \\
abscesso & metastático & síndrome relacionada ao lupus & arterite de células gigantes \\
Malária & linfomas & (deficiência de C1q) & hepatite granulomatosa reumática \\
Toxoplasmose & leucemias & - & corpo estranho intra-abdominal \\
Perihepatite gonocócica & - & - & febre por drogas \\
Salmonelose /esquistossomose & - & - & paniculite granulomatosa \\
Febre de Katayama & - & - & anemia hemolítica & - \\
- & - & - & deficiência de IgA
\end{tabular}


resultados. As autópsias fornecem os dados mais eloqüentes: dos nove pacientes falecidos sem diagnóstico, sete apresentavam doença para a qual havia tratamento adequado $^{24}$.

O bom relacionamento do médico com o paciente e sua família é imprescindível, pois a febre prolongada, na ausência de tratamento, até mesmo de antitérmicos, produz grande ansiedade. A longa série de exames negativos ou pouco elucidativos desgasta não só o paciente, como seus familiares, que começam a cobrar tratamento e a lembrar casos semelhantes, checando a competência do médico, que deverá ser compreensivo, mantendo, contudo, sua autoridade (Tabela 4).

Tabela 4 - Preceitos a serem seguidos na avaliação dos pacientes com FOI.

\section{Certifique-se de que o paciente tem febre}

0 exame clínico deve ser sistematizado, minucioso e repetido

Exclua doenças potencialmente graves e tratáveis (Figura 1)

Exclua febre provocada por medicamentos

Exclua imunodepressão subjacente

Procure trabalhar com exames complementares de qualidade

Pense sempre em associação de doenças

Defina critérios para a indicação de terapêutica de prova e laparotomia exploradora

Esteja presente quando outros colegas forem chamados a opinar

Mantenha boa relação médico-paciente

Há um tempo para agir e um tempo para esperar

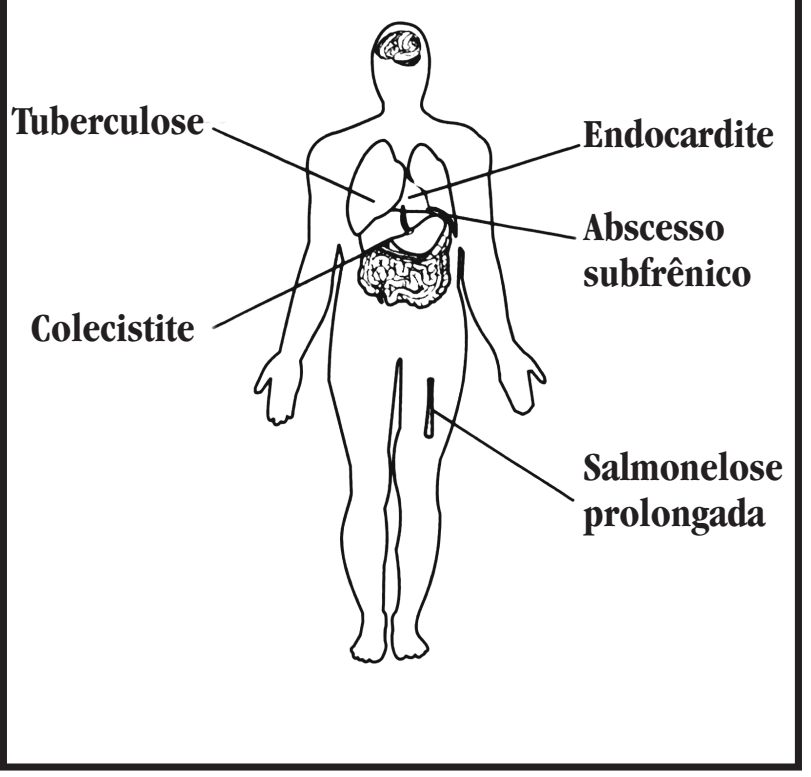

Figura 1 - Infecções graves e tratáveis.

\section{ANAMNESE E EXAME FÍSICO}

A anamnese e o exame físico deverão ser completos e repetidos periodicamente; quaisquer alterações devem ser valorizadas. A experiência tem mostrado que, freqüentemente, uma febre é obscura pelo fato de o médico não ter valorizado dados da história, do exame físico ou do exame complementar minimamente alterado.
Os pacientes geralmente começam seu relato pelo momento mais dramático ou importante, o que nem sempre coincide com 0 início efetivo da doença. A anamnese especial deve ser a mais completa e abrangente possível, não se limitando apenas a dados orgânicos, mas incluindo aspectos profissionais, viagens, ambiente de moradia e trabalho, contato com pessoas doentes ou animais. Deve-se investigar as endemias da região de origem do paciente (esquistossomose, malária, doença de Chagas, leishmaniose, paracoccidioidomicose, tuberculose) $)^{2}$.

0 médico também deve investigar completamente a história pregressa, indagando tratamentos (medicamentos usados, transfusões sanguíneas, acupuntura), moléstias anteriores e cirurgias, inclusive dentárias. Por vezes, sintomas considerados de pouca importância pelo paciente, por sua intensidade ou curta duração, constituem pistas importantes para o diagnóstico. Os aspectos psíquicos do paciente devem ser investigados; os pacientes manipuladores, devem nos fazer pensar em febre factícia ou fraudulenta (Tabela 5).

Tabela 5 - Anamnese dirigida na FOI.

\section{Indagações}

Viagens: duração, destino, doenças ocorridas, residências anterior e atual; descrever o local

Contato com portadores de doenças contagiosas

Atividade e hábitos sexuais

Contato com animais: gatos, cabras, bois

Picadas de insetos: mosquito, barbeiro

Hábitos alimentares: ingestão de carnes e outros alimentos crus, leite não-pasteurizado

Exposições profissionais: açougueiros, veterinários, trabalhadores em esgoto, trabalhadores do setor de saúde

Abuso de drogas injetáveis e álcool

Medicamentos: antibióticos, imunossupressores, antiinflamatórios, analgésicos, hormônios, tranqüilizantes, anticonvulsivantes

Doenças pregressas: cirurgias anteriores, valvulopatias cardíacas, doença dentária, icterícia, transfusões, acupuntura, tuberculose, neoplasias, doenças dos diversos aparelhos

Doenças familiares: exposição à tuberculose e outras doenças infecto-contagiosas, doenças hereditárias, colagenoses

Na história familiar deverão ser investigadas doenças semelhantes às do paciente, tanto as decorrentes de exposição comum (febre tifóide, esquistossomose aguda) quanto aquelas de origem genética (colagenoses, febre familiar do Mediterrâneo).

No exame físico devem ser pesquisadas lesões cutâneas (exantemas, petéquias, nódulos), lesões na orofaringe, seios paranasais, dentes, visceromegalias, linfadenomegalias, massas abdominais ou pélvicas e sopros cardíacos. A curva térmica deve ser pesquisada e comparada com os padrões clássicos. 0 exame físico deve ser repetido diariamente até o diagnóstico ser obtido. É importante anotar o dia de inicio da moléstia atual e o dia no qual o paciente está sendo examinado, pois em várias moléstias os sintomas e exames complementares variam com o tempo, obtendo-se resultados diferentes conforme a evolução da doença.

Não deve ser esquecido o exame de fundo de olho, boca, orofaringe, dentes e da região anal e reto. 


\section{DIAGNÓSTICO ETIOLÓGICO DA FOI}

Se a anamnese e o exame físico são fundamentais para 0 esclarecimento da FOI, os exames complementares normalmente serão decisivos. Não há roteiro padronizado de exames a serem pedidos; o médico deve sempre considerar os dados clínicos e epidemiológicos ao iniciar a propedêutica armada. Existem achados que sugerem infecção bacteriana ou neoplasia, apresentados na Tabela 6 .

Tabela 6 - Alguns aspectos que diferenciam a febre induzida por infecção bacteriana da induzida por neoplasia.

\section{Sugerem ou afastam INFECCÃO}

quanto maior a duração da síndrome febril, menor a probabilidade de origem infecciosa as doenças infecciosas geralmente são diagnosticadas no primeiro trimestre de estudo proteína C-reativa maior que $100 \mathrm{mg} / 1$ sugere infecção bacteriana ${ }^{28}$ teste com naproxeno negativo sugere infecção bacteriana ${ }^{4}$

a leucocitose, com desvio à esquerda, sugere infecção bacteriana

\section{Sugerem ou afastam NEOPLASIA}

a presença de mialgia e artralgia fala contra doença neoplásica.

teste do naproxeno positivo sugere febre de origem neoplásica.

perda de mais de $1 \mathrm{~kg}$ de peso corporal por semana sugere neoplasia

as neoplasias são mais raras quando a febre tem duração superior a um ano ${ }^{12}$

eosinofilia sugere helmintose (especialmente esquistossomose) ou neoplasia (principalmente doença de Hodgkin) ${ }^{16}$

Na investigação da FOI é que o clínico deverá mostrar maior conhecimento na indicação e nas limitações dos exames complementares ${ }^{16}$. Considerando-se a rápida e contínua proliferação desses exames caberá ao médico assistente orientarse com radiologistas ou patologistas, a fim de evitar a superposição de exames com finalidades semelhantes. Os pedidos não deverão ser feitos de forma burocrática, mas de preferência pessoalmente e acompanhados de relatório historiando o caso. Os exames devem ser realizados ou revistos por pessoas reconhecidamente competentes.

Vários exames poderão ser feitos ainda em nível ambulatorial, outros exigirão hospitalização. 0 paciente deverá ter toda medicação suspensa, com exceção daquela indispensável.

Como regra geral, deve-se começar pelos exames menos invasivos, reservando-se os mais agressivos, como a laparotomia exploradora, para as fases finais. Além disso, deverá ser colhida, logo que o caso for reconhecido como FOI, uma amostra de sangue que será conservada a $4^{\circ} \mathrm{C}$. Essa amostra servirá para comparação futura dos títulos sorológicos, permitindo saber se os níveis de anticorpos estão subindo ou caindo durante a moléstia atual. Recomenda-se que as reações sorológicas não sejam pedidas rotineiramente, mas sim de forma ordenada e considerando-se a baixa especificidade de algumas reações (com falsos positivos mais freqüientes).

\section{EXAMES COMPLEMENTARES}

Alguns exames laboratoriais são freqüentemente inespecíficos, mas podem trazer subsídios para o diagnóstico de algumas doenças. Por exemplo, não é raro encontrar-se o leucograma alterado, com aumento ou redução do número global de leucócitos; este dado é pouco específico, mas o estudo da morfologia dos mesmos pode mostrar alterações importantes, como a presença de linfócitos atípicos ou de eosinofilia.

A velocidade de eritrossedimentação é outro destes exames de baixa especificidade, mas que em algumas situações pode ser muito útil, como, por exemplo, na arterite de células gigantes.

A dosagem da fosfatase alcalina é muito útil na propedêutica da FOI. Sua elevação habitualmente aponta o acometimento hepático e a necessidade de investigação deste órgão. Como existem duas frações, óssea e hepática, pode ser conveniente esclarecer a qual delas deve-se a elevação em certos casos.

Se a história e o exame físico não são sugestivos de nenhuma doença em particular, ou se há dificuldades para sua obtenção (pacientes com demência ou com distúrbios da fala), é lícito recorrer-se a certas rotinas de exames complementares, apresentadas nas Tabelas 7 e 8.

Tabela 7 - Exames laboratoriais na FOI.

\section{Hematologia e bioquímica sanguínea}

hemograma e hematoscopia*

velocidade de eritrossedimentação (30 e $60 \mathrm{~min}$ )*

pesquisa de hematozoários em gota espessa*

transaminases, fosfatase alcalina (muito útil), bilirrubinas*

eletroforese de proteínas*

uréia e creatinina

hormônios tireóideos: TSH e T4 livre

desidrogenase láctica

Culturas (aeróbios, anaeróbios e BAAR)

hemoculturas*: colher pelo menos três amostras com intervalos de quatro horas no primeiro dia e uma amostra no segundo e terceiro dias (de preferência coincidindo com picos febris)

culturas de urina e fezes

culturas de secreções corporais (escarro, lavado gástrico, derrame pleural, ascite, liquor, medula óssea).

\section{Urina e fezes}

urina rotina (elementos anormais e sedimentoscopia)

exame parasitológico das fezes* (empregar pelo menos dois métodos para pesquisa de helmintos e protozoários)

pesquisa de sangue oculto nas fezes

Sorologia

antiestreptolisina 0 (ASLO) (febre reumática)

fator antinúcleo (FAN)*

fator reumatóide

VDRL, FTA-abs (sífilis)

imunofluorescência e ELISA para Trypanosoma cruzi

pesquisa de anti-VEB (mononucleose infecciosa)

anticorpos antitoxoplasma (IgM e IgG)

reações de aglutinação anti-Brucella e anti-Salmonella typhi

sorologia para calazar

anticorpos anti-citomegalovírus

anti-HIV (SIDA/AIDS)

anti-VHB (anti-HBsAg, IgG e IgM anti-HBC)

proteína C-reativa (PCR) quantitativa

Testes cutâneos

PPD - se negativo, realizar outros testes cutâneos (tricofitina, candidina, Aspergillus) para excluir anergia

\section{Biópsias}

hepática (muito útil em doenças granulomatosas)

medula óssea (muito útil em doenças granulomatosas, em especial, quando há anemia, leucopenia, ou monocitose)

"Exames considerados úteis no rastreamento inicial. 
Tabela 8 - Exames de imagem na FOI.

Radiologia convencional: tórax, abdômen, coluna vertebral, ossos longos, crânio (tumores, sinais de abscesso, ar extraluminal): geralmente pouco úteis; dentes, seios paranasais: muito úteis

Ultra-sonografia*: muito útil na pesquisa de massas e coleções líquidas das regiões cervical, torácica, abdominal e pélvica

Ecocardiografia: muito útil (endocardite bacteriana)

Tomografia computadorizada*: muito eficiente na detecção de massas e coleções líquidas no crânio, tórax, abdômen e pelve

Ressonância magnética: muito útil (disponibilidade restrita)

Galium 67: detecção de abscesso e tumores moderadamente útil (geralmente empregada após US e TC negativos) ${ }^{20}$

Medicina nuclear: pulmão (embolia); ossos (tumores) - moderadamente útil

Trânsito intestinal (enterite regional); enema opaco (diverticulite, enterocolite) moderadamente útil; endoscopias (colonoscopia, esofagogastroduodenoscopia, endoscopia do delgado)

Outros exames contrastados (angiografias, colangiografias) estão indicados em poucos casos - pouco úteis

* São usados para guiar a punção diagnóstica de massas e coleções.

\section{BIÓPSIAS}

Após as culturas, as biópsias constituem o recurso propedêutico mais utilizado no esclarecimento das FOIs. Destas, as mais pedidas são as de linfonodos, medula óssea e hepática. Os linfonodos estão acometidos em diversas doenças infecciosas ou neoplásicas e sempre que estiverem aumentados devem ser biopsiados, até mesmo os da cadeia inguinal. Os métodos de imagem são úteis na localização de linfadenopatias profundas, retroperitoniais ou mediastinais ${ }^{8}{ }^{20}$.

Foi através dos estudos iniciais, mostrando a grande importância da biópsia hepática no diagnóstico da FOI, que a sua indicação passou a ser rotineira nesses casos. Atualmente, entretanto, considera-se mais apropriado realizar a biópsia quando existem evidências de doença hepática (sugerida por dados clínicos, laboratoriais ou métodos de imagem $)^{28}$. Da mesma forma, a laparoscopia é considerada exame muito útil quando há evidências de doença intra-abdominal. Os materiais obtidos por biópsia também devem ser cultivados para bactérias aeróbicas, anaeróbicas e micobactérias.

A biópsia de medula óssea deve ser realizada com freqüência na FOI, mesmo na ausência de alterações no sangue periférico. Leucemias, tuberculose miliar, brucelose, febre tifóide e calazar podem ser diagnosticados com esse exame.

\section{LAPAROTOMIA EXPLORADORA}

Em alguns pacientes, mesmo após extensa propedêutica não invasiva, o diagnóstico etiológico da FOI não será estabelecido. Nesses casos, pode ser necessária a realização de laparotomia exploradora ${ }^{8}$. Suas indicações têm se restringido com o advento dos novos métodos de imagem $\mathrm{e}$ da laparoscopia, mas ainda restam algumas doenças - como angeíte necrosante, que só serão descobertas por esse método. Alguns sinais que sugerem a presença de doença intra-abdominal são: dor abdominal, anemia e perda de peso progressivas; icterícia; hepato e/ou esplenomegalia; massas abdominais e alterações da função hepática. Em caso de ascite, o líquido deve ser colhido para citologia e cultura.

\section{TERAPÊUTICA DE PROVA}

As indicações para terapêutica de prova nos pacientes com FOI são muito restritas e devem ser feitas em condições bem definidas. Não existe motivo parta utilizar-se a terapêutica de prova, quando órgãos vitais, como coração, pulmão, rins ou cérebro, não estão seriamente comprometidos. A presença de febre, mesmo que o quadro impressione inicialmente, não justifica terapêutica intempestiva. Observam-se, com freqüência, tentativas terapêuticas iniciadas e abandonadas rapidamente, em favor de uma reavaliação clínico-laboratorial mais completa.

As desvantagens da terapêutica de prova são múltiplas. Geralmente recorre-se a antibióticos, corticosteróides e agentes antiblásticos, todos com efeitos colaterais potencialmente graves ou que podem obscurecer o quadro clínico já confuso, acrescentando mais febre, icterícia, farmacodermias, leucopenia, diarréia ou outros sintomas. Alguns medicamentos podem produzir melhora aparente sem atacar realmente a doença de base. Finalmente, a terapêutica de prova pode produzir efeitos adversos pelas expectativas que geram no paciente, tornando difícil e embaraçoso para este retirar a medicação e reiniciar a propedêutica após o fracasso inicial. Para que isso não ocorra, caso se opte pela terapêutica de prova, o paciente e seus familiares deverão estar completamente a par de sua indicação e da possibilidade de fracasso (ver Tabela 9).

Tabela 9 - Indicações da terapêutica de prova.

Doenças graves: rapidamente progressivas, com ameaça à estabilidade de sistema fisiológico principal. Mesmo nessas situações, sempre há tempo suficiente para coleta de material para exames, inclusive culturas e biópsias

Doenças crônicas: progressivas, nas quais, após propedêutica exaustiva, a maioria das possibilidades diagnósticas foi excluída, restando uma ou duas mais prováveis, sendo que existe tratamento eficaz para pelo menos uma delas

Ao se decidir pela terapêutica de prova, cumpre observar algumas normas: Evitar drogas às quais o paciente é sabidamente hipersensível

Atribuir significação diagnóstica à terapêutica de prova, isto é, o medicamento empregado deverá ter espectro limitado, se possível, específico para determinada doença Verificar a dose do medicamento e qual o tempo necessário para a sua ação

\section{FEBRE NOSOCOMIAL}

É uma doença associada à hospitalização e decorre de acontecimentos comuns no ambiente hospitalar, tais como, procedimentos cirúrgicos, sondagem urinária, intubação endotraqueal, cateteres, medicamentos, imobilização que se associa à embolia pulmonar de repetição. Vale a pena lembrar a colite pelo Clostridium difficile e a febre por drogas. Faltam estudos bem controlados neste ambiente para se definir melhor o perfil e a importância de cada evento na causa da febre nosocomial ${ }^{18}$.

\section{FEBRE NO NEUTROPÊNICO}

Os episódios de febre são freqüentes no neutropênico. Somente 35\% dos casos de FOI nestes casos respondem a antibióticos de largo espectro. Excluídas as doenças 
bacterianas, as outras causas mais comuns são: doenças fúngicas, virais (CMV, herpes, influenza e outros), efeitos tóxicos de quimioterápicos, febre por drogas ${ }^{6}$.

Em pacientes com imunodeficiência por depressão predominante da imunidade celular, as infecções bacterianas piogênicas possuem papel secundário como demonstrado recentemente no estudo de Chang e cols ${ }^{5}$ em pacientes transplantados.

\section{FEBRE NA SÍNDROME DA IMUNODEFICIÊNCIA ADQUIRIDA (SIDA/AIDS)}

É muito comum, tendo estas pessoas inúmeras causas para sua ocorrência, tais como: infecções oportunistas, febre pelo próprio HIV, neoplasias, reações a drogas. Na fase aguda da doença, a febre pelo HIV juntamente com outros sintomas (mialgia, erupção cutânea, cefaléia, linfadenopatia) constitui uma síndrome semelhante ao quadro de mononucleose infecciosa. As reações às drogas são mais comuns nos pacientes HIV positivos do que na população em geral, podendo ocorrer isoladamente, sem erupção cutânea ou eosinofilia. 0 diagnóstico de febre pelo HIV constitui diagnóstico de exclusão, somente devendo ser feito após investigação completa das outras causas de febre.

Apesar da ampla literatura sobre SIDA, existem poucos trabalhos que abordam a FOI neste grupo. Entretanto, na prática clínica diária, este representa um problema freqüente, sendo que, em alguns trabalhos, ocorrem em $8,2 \%$ a $21 \%$ dos pacientes com SIDA 391415172122 .

Além disso, as etiologias da FOI apresentam uma variação geográfica importante com poucos conhecimentos sobre suas características em nosso país. A Tabela 10 resume as principais causas de FOI em estudos de diferentes locais.

Tabela 10 - Principais causas de FOI na SIDA/AIDS.

\begin{tabular}{|c|c|c|c|c|c|c|}
\hline \multirow[b]{2}{*}{ Causas } & \multicolumn{2}{|c|}{$\begin{array}{l}\text { Bissuel cols }{ }^{3} \\
\text { França, } 1994\end{array}$} & \multicolumn{2}{|c|}{$\begin{array}{l}\text { Miralles cols }{ }^{21} \\
\text { Espanha, } 1994\end{array}$} & \multicolumn{2}{|c|}{$\begin{array}{c}\text { Lambertucci cols }^{17} \\
\text { Brasil, } 1999\end{array}$} \\
\hline & $\mathrm{n}=57$ & $\%$ & $\mathrm{n}=50$ & $\%$ & $\mathrm{n}=55$ & $\%$ \\
\hline Tuberculose & 10 & 17,5 & 21 & 42,0 & 15 & 43,9 \\
\hline MAC* $^{*}$ & 10 & 17,5 & 7 & 14,0 & 5 & 12,2 \\
\hline Pneumocistose & 3 & 5,2 & 1 & 2,0 & 6 & 14,7 \\
\hline Meningite criptocócica & 1 & 1,7 & - & - & 3 & 7,3 \\
\hline Citomegalovirose & 5 & 8,7 & 1 & 2,0 & - & - \\
\hline Leishmaniose & 4 & 7,0 & 7 & 14,0 & - & - \\
\hline Toxoplasmose & 2 & 3,5 & 1 & 2,0 & 1 & 2,4 \\
\hline Sinusite & 2 & 3,5 & - & - & 2,0 & 4,8 \\
\hline Histoplasmose & - & - & - & - & 2 & 4,8 \\
\hline Sífilis & - & - & - & - & 1 & 2,4 \\
\hline Isosporíase & - & - & - & - & 1 & 2,4 \\
\hline Febre medicamentosa & - & - & 1 & 1,7 & 1 & 2 \\
\hline Linfoma & 4 & 7,0 & 2 & 4,0 & 4 & 7,3 \\
\hline Sem diagnóstico & 8 & 14,0 & 6 & 12,0 & 10 & 18,3 \\
\hline
\end{tabular}

*Complexo Mycobacterium avium

\section{FEBRE NO IDOSO}

Nos pacientes idosos, a resposta febril pode estar ausente ou mínima em 20 a 30\% dos casos, mesmo na presença de infecção grave. Além de atrasar o diagnóstico, a ausência de febre acarreta mau prognóstico. 0 paciente idoso é considerado febril nas seguintes situações:

- Elevação persistente da temperatura maior que $37,2^{\circ} \mathrm{C}$ acima da temperatura basal

- Elevação $\geq 1,3^{\circ} \mathrm{C}$ na temperatura basal em qualquer sítio ${ }^{29}$

- Temperatura oral ou timpânica $>37,2^{\circ} \mathrm{C}$

- Temperatura retal $>37,5^{\circ} \mathrm{C}$ em várias ocasiões

Ao contrário do paciente mais novo, a presença de febre em paciente idoso indica infecção grave, geralmente bacteriana, e propedêutica adequada deve ser iniciada para descobrir o foco dessa infecção.

A abordagem adequada da FOI no paciente idoso engloba história clínica e exame físico bem feitos, enfocando os sinais e sintomas de doenças intra-abdominais, doenças cardíacas, tuberculose, desordens músculo-esqueléticas e tumores. Radiografia de tórax, exames laboratoriais básicos, estudos de imagem do abdome, hemoculturas e ecocardiograma devem ser realizados ${ }^{29}$. Todas as drogas dispensáveis deverão ser interrompidas assim como drogas essenciais deverão ser reavaliadas caso a febre persista ${ }^{19}{ }^{30}$.

\section{REFERÊNCIAS BIBLIOGRÁFICAS}

1. Arnow PM, Flaherty JP. Fever of unknown origin. Lancet 350: 575-580, 1997.

2. Amato Neto V, Mendonça JS. Febre de Origem Indeterminada. Sarvier Editora de Livros Ltda, São Paulo, 1984.

3. Bissuel F, Leport C, Perronne C, Longuet P, Vilde JL. Fever of unknown origin in HIV-infected patients: a critical analysis of a retrospective series of 57 cases. Journal of Internal Medicine 236: 529-535, 1994.

4. Chang JE, Gross HM. Utility of naproxen in the differential diagnosis of fever of undetermined origin in patients with cancer. American Journal of Medicine 76: 597-603, 1984.

5. Chang FY, Singh N, Gayowski T, Wagener MM, Marino IR. Fever in liver transplant recipients: changing spectrum of etiologic agents. Clinical Infectious Diseases 26: 59-65, 1998.

6. Corey L, Boekt M. Persistent fever in patients with neutropenia. New England Journal of Medicine 346: 222-224, 2002.

7. Durack DT, Street AC. Fever of unknown origin - reexamined and redefined. Current Clinical Topics in Infectious Diseases 11: 35-51, 1991.

8. Greenall MJ, Gough MH, Kettewell MG. Laparotomy in the investigation of patients with pyrexia of unknown origin. Surgery 70: 356-357, 1983.

9. Knobel H, Salvadó SM, Gimeno LJ, López-Colomes JL, Saballs P, Drobnic L, Diez A. Fiebre de origem desconocido en pacientes com infección por el vírus de la inmunodeficiencia humana. Estudio de 100 casos. Revista Clinica Espanhola 196: 349-353, 1996.

10. Konecny P, Davidson RN. Pyrexia of unknown origin in the 1990s: time to redefine. British Journal of Hospital Medicine 56: 21-24, 1996. 
11. Knockaertd C, Vanderschueren S, Blockmans D. Fever of unknown origin in adults: 40 years on. Journal of Internal Medicine 253: 263-275, 2003.

12. Lambertucci JR. Febre. In: Lopez M, Laurentys-Medeiros J (eds) Semiologia Médica - As Bases do Diagnóstico Clínico. Livraria e Editora Revinter, Rio de Janeiro, p. 66-77, 2004.

13. Lambertucci JR. Febre: diagnóstico e tratamento. Rio de Janeiro: Editora Medsi, p. 321, 1991.

14. Lambertucci JR, Franca BM, Leite VH. Disseminated histoplasmosis and primary central nervous system lymphoma. Revista da Sociedade Brasileira de Medicina Tropical 37: 194-195, 2004.

15. Lambertucci JR, Franco R, Queiroz LC. Cryptococcal meningoencephalitis and pulmonary nodule in a non-HIV-infected immunocompetent patient. Revista da Sociedade Brasileira de Medicina Tropical 38: 207-208, 2005.

16. Lambertucci J, Gerspacher-Lara R. Febre de origem indeterminada: preceitos, pistas clínicas e exames complementares. Revista da Sociedade Brasileira de Medicina Tropical 27: 31-37, 1994.

17. Lambertucci JR, Rayes A, Nunes F, Landaziri-Palacios JE. Prolonged fever in patients with the acquired immunodeficiency syndrome in Brazil. Report on 55 cases. Revista do Instituto de Medicina Tropical de São Paulo 41: 27-32, 1999.

18. Mackowiak PA, Durack DT. Fever of unknown origin. In: Mandell GL, Bennett JE, Dolin R (eds) Principles and Practice of Infectious Diseases, sixth edition, Elsevier, Philadelphia, p. 718-729, 2005.

19. Magaldi C. Febre de origem indeterminada. Análise de 102 casos. Revista do Hospital de Clínicas da Faculdade de Medicina de São Paulo 21: 315-325, 1966.
20. Mcneil BJ, Sanders R, Alderson PO, Hessel SJ. A prospective study of computed tomography, ultrasound and gallium imaging in patients with fever. Radiology 139: 647-653, 1981.

21. Miralles P, Moreno S, Pérez-Tascón M, Cosín J, Diaz MD, Bouza E. Fever of uncertain origin in patients whit the human immunodeficiency virus. Clinical Infectious Diseases 20: 872-875, 1995.

22. Nobre V, Braga E, Rayes A, Serufo JC, Godoy P, Nunes N, Antunes CM, Lambertucci JR. Opportunistic infections in patients with AIDS admitted to an university hospital of the Southeast of Brazil. Revista do Instituto de Medicina Tropical de Sao Paulo 45: 69-74, 2003.

23. Pereira NG. Febres prolongadas de origem obscura. In: Tavares W, Marinho LAC (eds) Rotina de Diagnóstico e Tratamento das Doenças Infecciosas e Parasitárias. Editora Atheneu, São Paulo, p.1136-1150, 2005.

24. Petersdorf RG. FU0: how it has changed in 20 years. Hospital Practice 20: 84-89, 1985.

25. Petersdorf RG, Beeson PB. Fever of unexplained origin: report of 100 cases. Medicine 40: 1-30, 1961.

26. Tal S, Guller V, Gurevich A, Levi S. Fever of unknown origin in the elderly. Journal of Internal Medicine 252: 295-304, 2002.

27. Teixeira Junior AL, Nobre V, Lambertucci JR. Respiratory failure due to opportunistic diseases in AIDS. Revista da Sociedade Brasileira de Medicina Tropical 35: 411-412, 2002.

28. Voltarelli JC. Febre e inflamação. Medicina (Ribeirão Preto) 27: 7-48, 1994.

29. Whitehead TC, Davidson RN. Pyrexia of unknown origin: changing epidemiology. Current Opinion in Infectious Diseases 10: 134-138, 1997.

30. Yoshikawa TT. Fever in the elderly. Infections in Medicine 15: 704-706, 1998. 